Recent studies have focused on attachment and related variables to explain partner abuse. These studies have not included significant numbers of African American men. Path analysis was used to examine the relationship between interpersonal relatedness (i.e., attachment, social support, and sense of belonging) as mediated by affect (hopelessness and depression) to explain abusive behaviors in African American men arrested for partner abuse. Data were collected using self-administered questionnaires from a convenience sample of 69 African American men 18 to 69 years of age. The strongest effect was from sense of belonging in predicting severity-weighted frequency of physical, psychological, and sexual abuse. Preoccupation with closeness had a negative direct effect on severity-weighted frequency of sexual abuse. Hopelessness and depression did not act as mediators. Implications for further research are discussed.

\title{
Mediators of Attachment Style, Social Support, and Sense of Belonging in Predicting Woman Abuse by African American Men
}

\author{
LARRY B. RANKIN \\ University of Michigan/Eastern Michigan University \\ DANIEL G. SAUNDERS \\ REG A. WILLIAMS \\ University of Michigan
}

Progress has been made in identifying various risk factors for domestic violence, including distal factors, such as childhood exposure to violence, and proximal factors, such as unemployment (Holtzworth-Munroe, Smutzler, \& Bates, 1997; Jasinski \& Williams, 1998; Tolman \& Bennett, 1990). These findings are rarely replicated in samples of people of color. The need to uncover risk factors among people of color is especially important, given the higher than normal rates of lethal and nonlethal domestic violence in some of these groups, in particular, African Americans (Greenfield et al., 1998; Hampton, Carrillo, \& Kim, 1998).

Recent studies applying attachment theory and related theories to understand abusive behavior have not been replicated with exclusively African

Authors' Note: Correspondence regarding this article can be addressed to the first author at the Department of Nursing, Eastern Michigan University, 236A King Hall, Ypsilanti, MI 48197.

JOURNAL OF INTERPERSONAL VIOLENCE, Vol. 15 No. 10, October 2000 1060-1080

(C) 2000 Sage Publications, Inc.

1060 
American samples. Such theories need to be tested with contrasting theories that stress social structural theories, for example theories that include social class and community disorganization. These factors appear to be explanations for the higher rates of African American domestic violence (Hampton et al., 1998). Both insecure attachment and social problems like unemployment are likely to lead to a lower sense of belonging and less social support. In turn, all of these factors are likely to lead to a greater sense of hopelessness, more depression, and ultimately to violence.

The purpose of this study was to determine if attachment styles, sense of belonging, social support, and unemployment were related to partner abuse in a sample of African American men who batter. The study further sought to determine if hopelessness and depression mediated these predictors of abuse.

Disruptions in the parent-child attachment bond have recently been the focus of studies of men who batter (Dutton, Starzomski, \& Ryan, 1996). Stosny (1993) posited that abusers have immature ways of processing powerful affective information and that attachment figures serve as illusory reflections of the inner self, a self that was unlovable and incompetent.

Traumatic childhood experiences of men who batter may lead to preoccupied, distancing, or anxious attachment styles and corresponding personality disorders. These attachment styles in turn may lead to hostility toward attachment figures (i.e., intimate partners), a sense of entitlement, dependency, and subsequent controlling behavior and violence (Dutton, van Ginkel, \& Landolt, 1996; Murphy, Meyer, \& O'Leary, 1993). Anxiety over abandonment is one of the risk factors for domestic violence (Dutton, Saunders, Starzomski, \& Bartholomew, 1994; Roberts \& Noller, 1998).

Several attachment typologies have been constructed. Bartholomew and Horowitz (1991) identified four distinct attachment styles present in childhood that persist in adult romantic relationships: secure, preoccupied, dismissing, and fearful. Lopez (1995) found three styles that may be linked to behaviors in adult life: secure, anxious-ambivalent, and avoidant. For this study, a five-factor typology developed by Feeney, Noller, and Hanrahan (1994) was used to assess more subtle differences in insecure types. The five factors were Confidence, Discomfort With Closeness, Need for Approval, Preoccupation With Relationships, and Relationships as Secondary. In this typology, the Confidence factor corresponds to the secure style. The Need for Approval subscale and the Preoccupation With Relationships subscale correspond with the anxious-ambivalent type. The Discomfort With Closeness subscale and Relationships as Secondary subscale correspond to the avoidant type. Childhood attachment patterns appear to be linked to a sense of belonging (Hagerty, Lynch-Sauer, Patusky, \& Bouwsema, 1993), to a sense of hope- 
lessness (Melges \& Bowlby, 1969), and to depression (Diamond \& Blatt, 1994); associations to be reviewed in more depth later.

Partner abuse may decrease through the inhibitory effects of social support and attachment to family, friends, and relatives (Hirschi, 1969). Lackey and Williams (1995) measured adult attachment by asking the men how important it was to have special occasions and activities with their partners and friends and to attend meetings and clubs. They were then asked how likely it would be that they would receive sanctions for those negative behaviors and the effect of such sanctions on their continuance of the negative behaviors. Results showed that men who developed strong attachments to and perceive negative sanctions from significant others are more likely to be nonviolent toward their female partners. However, if the significant others support violence against women, the results may be the opposite (DeKeseredy, 1988).

A sense of belonging may be a direct outcome of social support and healthy adult attachments. Hagerty, Lynch-Sauer, Patusky, Bouwsema, and Collier (1992) define sense of belonging as "the experience of personal involvement in a system or environment so that persons feel themselves to be an integral part of that system or environment" (p. 173). Sense of belonging has two major components: "valued involvement", or the experience of feeling valued, needed, and accepted, and "fit", which is the person's perception that his or her characteristics articulate or complement the system or environment (p. 173).

Without healthy attachment, social supports, and a sense of belonging, hopelessness may result. Hopelessness has cognitive and affective dimensions. Persons who are hopeless demonstrate a lack of anticipation of the future and show inertia in taking action to achieve goals and self-expectations. Beck, Brown, Berchick, Stewart, and Steer (1990) found that hopelessness may be considered a risk factor for serious depressive symptoms and suicide. Abraham, Metalsky, and Alloy (1989) presented a revision of a theory of helplessness and depression called the hopelessness theory of depression. Hopelessness and its link to depression have been revealed in a number of studies (e.g., Abraham et al., 1989; Beck et al., 1990).

Batgos and Leadbeater (1993) linked attachment styles to depressive disorders. Insecurely attached individuals, especially those who demonstrate anxious/ambivalent or avoidant type attachment behaviors, appear to be at risk for depression (Diamond \& Blatt, 1994). A decreased sense of belonging has also been associated with a higher level of depression (Hagerty \& Williams, 1999; Hagerty, Williams, Coyne, \& Early, 1996). Depression, in turn, has been linked empirically to domestic violence (Davidovich, 1990; Tolman \& Bennett, 1990). 
The above risk factors are especially salient for African American men. Their lack of a sense of belonging to the larger society and its link with hopelessness was noted in a review by Allen-Meares and Burman (1995). Their review focused on problems African American men face in our society, including violence, racial inequities, helplessness and hopelessness, depression, frustration, and devaluation of African Americans. They found that a climate of alienation and being physically assaulted could create a sense of hopelessness when persons feel they do not fit in socially. Williams (1998) applied the unique stresses of African American men to an analysis of domestic violence. Stress in the community combined with fewer resources, generalization of a "tough guy" image, and displacement of anger from the social environment may help to explain their violence against intimates. Hampton et al. (1998) reviewed studies that point to residential mobility and poverty within the context of community change as risk factors for domestic violence by African American men.

Few studies have been conducted on the nature of violence between African American intimates (Lockhart \& White, 1989). Furthermore, most studies compare racial groups without investigating patterns within groups and no studies were found that focused on links between interpersonal relatedness variables (attachment, social support, sense of belonging) and partner abuse in African American males. Such a focus is important because African American abusers may show a different pattern among these variables than other populations.

Following from the above review of research, a major goal of this study was to determine if hopelessness and depression were mediators between interpersonal relatedness variables and partner abuse in a population of African American males. Path models were proposed for the prediction of physical, psychological, and sexually abusive behaviors, including direct and indirect links from more distal variables (e.g., attachment) to more proximal variables (depression and hopelessness) through social support and sense of belonging. We proposed the following hypotheses:

Hypothesis 1: Severity and frequency (weighted by severity) of violence will be positively related to insecure attachment style, decreased social support, and decreased sense of belonging.

Hypothesis 2: The effect of insecure attachment style, employment, and perceived social support on severity and frequency (severity weighted) of partner abuse will be mediated by hopelessness.

Hypothesis 3: The effect of insecure attachment style, employment, and social support on severity and severity-weighted frequency of partner abuse will be mediated by depression. 
Hypothesis 4: The effect of sense of belonging on severity and severity-weighted frequency of partner abuse will be mediated by hopelessness.

Hypothesis 5: The effect of sense of belonging on severity and severity-weighted frequency of partner abuse will be mediated by depression.

\section{METHOD}

\section{Participants}

The sample consisted of 69 African American men who had been arrested on charges of domestic violence from the same midwestern state district court (see Table 1). All participants were 18 years old or older with a mean age of $31(S D=11)$. The average years of education was $12(S D=2)$. Approximately half of the sample $(51 \%)$ was unemployed, with $62 \%$ having a yearly income of less than $\$ 10,000,34 \%$ making between $\$ 10,000$ and $\$ 40,000$, and only $4 \%$ earning more than $\$ 40,000$ (see Table 1 ).

\section{Measures}

General Information Questionnaire. Each participant completed a 28-item questionnaire that asks for demographic information on age, race, ethnicity, education, employment, income, and gender. Participant's employment status was used from this questionnaire as an independent variable.

Measure of Wife Abuse (MWA). The MWA (Rodenburg \& Fantuzzo, 1993) is a 60-item, self-report measure of the frequency of abusive behaviors and the impact of the abuse. The original scale was developed for use with female victims. The scale was modified for male abusers in the present study. The scale has four subscales: physical abuse, nonverbal psychological abuse, verbal psychological abuse, and sexual abuse. The two psychological abuse subscales were combined because of their high correlation (.73). Rodenburg and Fantuzzo (1993) reported the alpha coefficient of reliability for the four scales as ranging from .73 to .94 , with the total scale of .93 . In the present study, the Cronbach's alpha coefficients for the subscales were (a) physical abuse $=.75$, (b) sexual abuse $=.54$, (c) nonverbal psychological abuse $=.75$, and (d) verbal psychological abuse $=.77$. The alpha coefficient for the combined psychological abuse subscale was .80 . Validity of the MWA was demonstrated by correlating the subscales with the Conflict Tactics Scales.

The MWA was weighted in this study in the following way: MWA items were rated by six mental health and court experts who work with abused 
TABLE 1: Sociodemographic Characteristics of the Sample in the Study

\begin{tabular}{lcccccc}
\hline Variable & Frequency & Percentage & M & SD & Minimum & Maximum \\
\hline Age & & 32 & 31 & 11 & 18 & 69 \\
18 to 25 & & 52 & & & & \\
26 to 40 & & 16 & & & & \\
41 to 69 & 35 & 51 & & & & \\
Education (years) & 6 & 9 & & & & \\
Employment & 1 & 1 & & & & \\
Unemployed & 24 & 35 & & & & \\
Part-time & 3 & 4 & & & & \\
Retired & & & & & \\
Full-time employed & 43 & 62 & & & \\
Other & 15 & 22 & & & & \\
Yearly income $(\$)$ & 8 & 12 & & & & \\
0 to 9,999 & 1 & 2 & & & & \\
10,000 to 24,999 & 1 & 1 & & & \\
25,000 to 39,000 & 1 & 1 & & & \\
40,000 to 54,999 & & & & & \\
55,000 to 69,000 & & & & & \\
More than 70,000 & & & & & \\
\hline
\end{tabular}

women. The experts were instructed to rate the items for severity into mild, moderate, severe, and very severe categories based on their professional work with battered women. When at least three of the raters agreed on the level of severity of abuse, the items were placed in the corresponding category. Three of the experts agreed on level of severity of abuse for 60 of the 69 items on the MWA, whereas for the remaining 9 items, fewer than three raters agreed. The remaining 9 items were categorized by the investigator who assigned the raters' highest severity ratings for those items. The items were then weighted for their severity with mild items multiplied by 1 , moderate items multiplied by 2 , severe items multiplied by 3 , and very severe items multiplied by 4 . Item scores reported by the participants were computed into subscales for physical abuse (severity-weighted frequency of physical abuse), psychological abuse (severity-weighted frequency of psychological abuse), and sexual abuse (severity-weighted frequency of sexual abuse). Data from the participants' police records were also examined for evidence of physical violence against their partner (i.e., pushing or hitting their partner or whether the victim had been hurt during the incident of arrest) and ratings were assigned accordingly.

A physical abuse severity scale was constructed regardless of frequency on a 4-point scale called severity of physical abuse scale $(1=$ mild, $2=$ moder- 
ate, $3=$ severe, and $4=$ very severe $)$. To accomplish this, items that were rated by the experts were recoded. Item scores were computed for scores greater than 0 . In addition, participants who reported no physical abuse, but had evidence in their probation record of pushing the victim, received a score of at least 1 . If participants reported no violence, but there was evidence in their record of a weapon being used against their partner or if the victim was hurt in the violent incident, they received a score of 2 . In this study, "weapons" included guns and knives as well as other less lethal items that inflict physical injury (e.g., plates). If participants were charged with aggravated assault, they received a score of 3 . If the participants had evidence of pushing a partner, hurting the victim, and were charged with aggravated assault or if the participants had evidence of pushing a partner, hurting the victim, and had used a weapon against the victim, participants received a score of 4 .

Attachment Styles Questionnaire (ASQ). This questionnaire contains 40 statements derived from five factors or subscales that categorize an individual's attachment style. The five factors were (a) Confidence (in self and others), (b) Discomfort With Closeness, (c) Need for Approval, (d) Preoccupation With Relationships, and (e) Relationships as Secondary. Content validity of the ASQ was established using several measures with a subsample of 295 psychology majors from a total sample of 470 university students (Hazan \& Shaver, 1987). Pairwise correlations between the five subscales of the ASQ were significant. The Confidence subscale correlated negatively with the other four subscales. The other four subscales, which measured insecure attachment styles, were positively intercorrelated. The avoidant attachment styles correlated with Discomfort With Closeness (.46) and correlated with Preoccupation With Relationships (.60) and Need for Approval (.27) styles. Analysis of variance (ANOVA) was conducted with secure avoidant and anxious/ ambivalent groups compared on the five subscales. On the Confidence subscale, secure individuals had higher scores than any other group. For Discomfort With Closeness, the secure group scored significantly lower than any other group. Anxious/ambivalent individuals scored higher than any other group on the Preoccupation With Relationships subscale. The anxious/ ambivalent individuals also scored higher on Need for Approval and Preoccupation With Relationships subscales than the other groups. The Cronbach's alpha coefficients reported for the subscales were (a) .80 for Confidence (in self and others), (b) .84 for Discomfort With Closeness, (c) .79 for Need for Approval, and (d) .76 for Preoccupation With Relationships and Relationships as Secondary. For the major analyses in the present study, three of the insecure factors were collapsed into one scale measuring the overall effect of insecure attachment styles. 
Personal Resource Questionnaire-Part 2 (PRQ-85). The social support portion of the PRQ-85 is composed of 25 statements using a Likert-type scale. Weinert and Brandt (1987) defined social support to include (a) provision for attachment/intimacy, (b) social integration, (c) opportunity for nurturant behavior, (d) reassurance of worth as an individual and in role accomplishments, and (e) the availability of informational, emotional, and material help. Cronbach's alpha coefficients were reported between .85 and .93 using several samples that ranged from 45 to more than 1000 participants. Convergent validity was established between Part 2 of the PRQ-85 and other social support scales including (a) the Social Support Scales by Lin, Dean, and Ensel (1981); (b) Norbeck Social Support Questionnaire (Norbeck, Lindsey, \& Carrieri, 1981); and (c) the Interpersonal Support Evaluation List. Significant intercorrelations between Part 2 of the PRQ-85 and these scales were $.49, .25,74$, and .40 , respectively (Brandt \& Weinert, 1981). The Cronbach's alpha coefficient for the present study was .85 .

Sense of Belonging Instrument (SOBI). The SOBI is a self-report instrument designed to measure sense of belonging in adults. It consists of two separately scored scales, SOBI-P (psychological state) and SOBI-A (antecedents). The SOBI-P scale only was used in this study. SOBI-P measures a person's sense of fit and of being valued within an interpersonal relationship. Test-retest reliability on the initial SOBI was .84 for the SOBI-P with 379 community college students over 8 weeks (Hagerty et al., 1992). Cronbach's alpha coefficients in the present study were .94 for the SOBI-P. Content validity of the SOBI was established with seven expert panelists. Item content validity ranged from .50 to 1.00 with the entire instrument's validity being .83. Construct validity was established using factor analysis, contrasted groups consisting of college students, depressed patients, and Catholic nuns, and scale correlation with measures of loneliness, reciprocity, and social support (Hagerty \& Patusky, 1995). African Americans made up 23\% of the community college students surveyed in that study. The SOBI has also been used in other studies with African Americans and has been found to be a valid instrument for use with this population.

Grimm State-Trait Hope Inventory Self Evaluation Scale (STHI). The instrument consists of 40 statements that relate to the individual's feelings of hope and hopelessness. The scale is divided into two 20 -item subscales that represent the state (how an individual feels at the time of the interview) and trait (how the individual usually feels) dimensions of hopelessness. Only the trait subscale was used in this study. Grimm (1990) reported the trait subscale alphas as ranging from .75 to .99. Cronbach's alpha coefficients for the pres- 
ent study were .87 for the trait subscale. In Grimm's study, content validity for the STHI scale was deemed adequate by calculating the average congruency percentages of three experts. Construct validity of the scale was supported by hypothesis testing and comparing the conceptual relationships between hope and spiritual well-being with the Spiritual Well-Being Scale (Ellison, 1983). Grimm reported Pearson product-moment correlations of .60 with the Spiritual Well-Being Inventory and hope state and .63 with the hope trait. The hope state scale was found to be negatively correlated ( $r=$ -.43) with the Brief Symptom Inventory (Grimm, 1990).

Beck Depression Inventory (BDI). The BDI is a self-report measure designed to measure the severity of depression. The questionnaire consists of 21 groups of statements measuring affective, cognitive, motivational, and psychomotor components of depression. Reliability estimates have ranged from .78 to .93 . Cronbach's alpha coefficient for the present study was .92 . This instrument has strong concurrent validity when tested with other measures of depression (Beck, Steer, \& Garbin, 1988).

\section{Procedures}

Individuals who were on probation for domestic violence charges were approached and asked to participate in the study. Informed consent forms were reviewed with the potential participants at the initial contact. Of 76 probationers who were contacted and who met the criteria for the study, 69 African American males agreed to participate. Probationers who agreed to be in the study were given a packet of the measures for self-administration. Due to the limited number of studies available on African American partner abusers and the need to decrease the possibility of a Type II error, we chose the value of $p \leq .10$ for testing statistical significance. Following descriptive and bivariate statistics, a series of multiple regression analyses were conducted to determine the links between the proposed variables in a path model.

\section{RESULTS}

Table 2 summarizes the participants' mean scores, standard deviations, and theoretical scale ranges for the dependent, independent, and mediating variables. Police records were used to verify claims of no usage of physical abuse by the participants. In all but 5 cases out of 69 , there was evidence in the police records of at least one physically abusive act perpetrated by the participants against their partners. Data gathered from participants' police records 
TABLE 2: Means, Standard Deviations, and Theoretical Scale Ranges for the Variables

\begin{tabular}{lrrl}
\hline Variable & \multicolumn{1}{c}{ M } & \multicolumn{1}{c}{ SD } & Theoretical Range \\
\hline Partner abuse & & & \\
$\quad$ Physical abuse & 386.69 & 1764.38 & Unlimited \\
Psychological abuse & 3126.63 & 8728.59 & Unlimited \\
Severity of physical abuse (police report) & 2.17 & 1.33 & $1-4$ \\
$\quad$ Sexual abuse & 35.30 & 182.24 & Unlimited \\
Attachment styles & & & \\
$\quad$ Insecure styles & 103.13 & 24.75 & $32-192$ \\
Discomfort With Closeness & 36.71 & 10.33 & $10-60$ \\
Need for Approval & 18.86 & 6.83 & $7-42$ \\
Preoccupation With Relationships & 26.55 & 8.10 & $8-48$ \\
$\quad$ Relationships as Secondary & 21.00 & 6.28 & $7-42$ \\
Social support & 129.24 & 21.32 & $25-175$ \\
Sense of belonging & & & \\
$\quad$ Psychological & 53.86 & 12.36 & $18-72$ \\
Hopelessness & & & \\
Future orientation & 25.59 & 7.41 & $11-55$ \\
Goal planning & 19.39 & 6.21 & $9-45$ \\
Relationships & 24.41 & 5.37 & $10-50$ \\
Taking action & 21.34 & 6.29 & $10-50$ \\
STHI (trait) & 46.50 & 11.84 & $20-100$ \\
Beck Depression Inventory & 13.62 & 12.24 & $0-63$ \\
\hline
\end{tabular}

NOTE: STHI = Grimm State-Trait Hope Inventory Self Evaluation Scale.

showed that $44(64 \%)$ of the victims were hurt. The police records also indicated that weapons were used by $15(21 \%)$ of the participants against their partners in the 6 months before arrest.

\section{Bivariate Analysis}

Table 3 shows the zero-order Pearson correlation coefficients computed to determine the relationships among the partner abuse, interpersonal relatedness variables (attachment styles, social support, and sense of belonging), and mediating variables (hopelessness and depression). Scores on the severityweighted frequency of physical abuse subscale, severity of physical abuse, and the severity-weighted frequency of psychological abuse subscale were significantly related to each other as expected (.51 to .98), with the lowest correlation among the dependent variables between the severity of physical abuse and the severity-weighted frequency of sexual abuse subscales.

Scores on the severity-weighted frequency of physical abuse, severity of physical abuse, and severity-weighted frequency of psychological abuse 


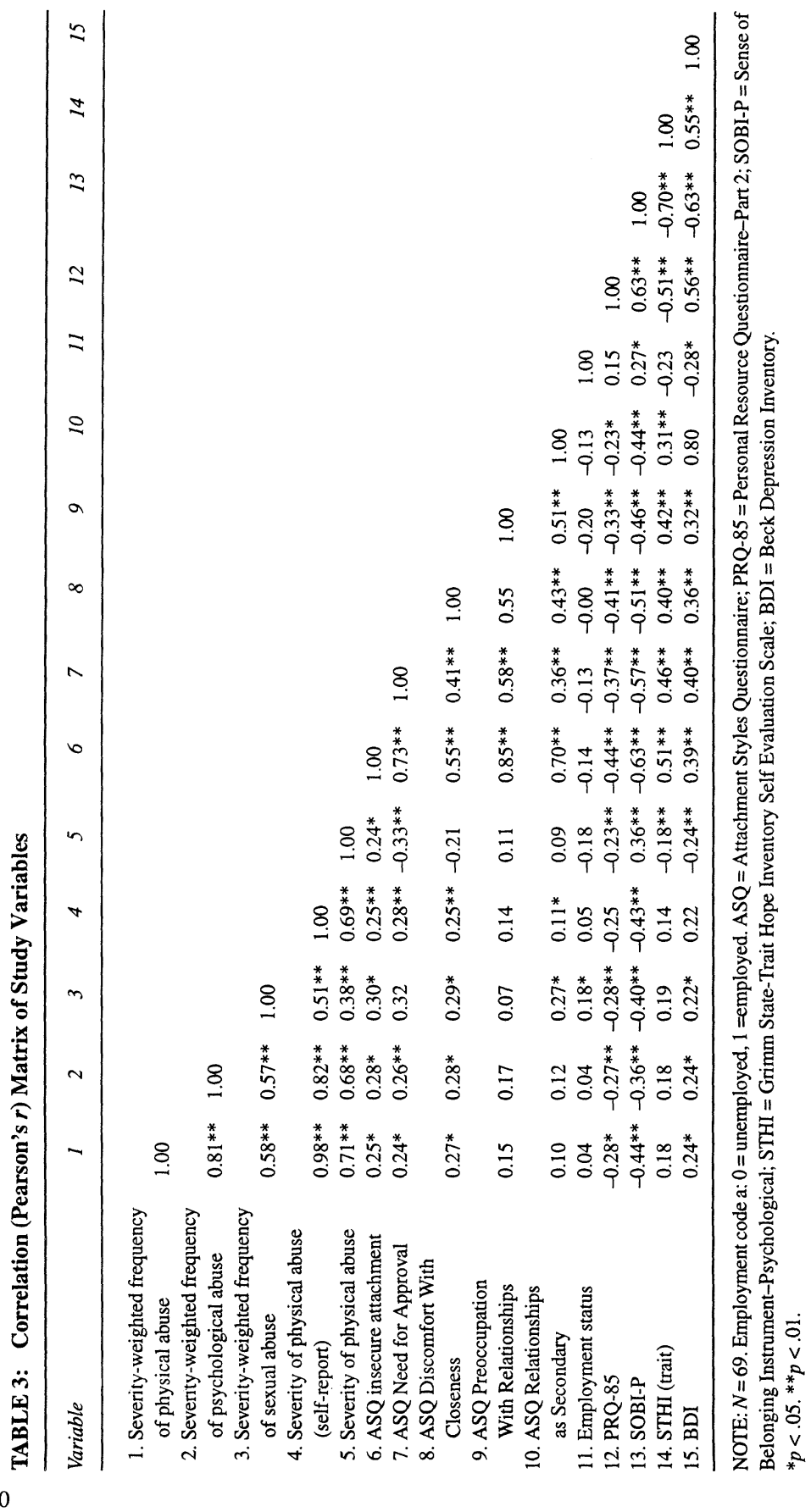


subscales were significantly correlated with two of the insecure attachment subscales and the BDI scores $(r=.24$ to .27$)$. The severity-weighted frequency of sexual abuse scores were significantly related to ASQ insecure attachment scores Need for Approval and Discomfort With Closeness $(r=$ .30). Significant negative relationships were found between the severity-weighted frequency of physical abuse, severity of physical abuse, and the weighted psychological abuse variables and social support and SOBI-P scores $(r=-.25$ to -.44$)$. The severity-weighted frequency sexual abuse scores had significant negative relationships to the PRQ-85 (social support) and the SOBI-P ( $r=-.28$ to -.40$)$.

Participants' insecure attachment style scores were significantly and negatively related to scores on the hopelessness state subscale $(r=.51)$ and BDI $(r=.39)$. Insecure attachment styles scores showed significant negative relationships with participants' scores of social support $(r=-.44)$ and sense of belonging $(r=-.63)$.

Being employed was significantly related to sexual abuse and SOBI-P $(r=$ .27). Being employed had significant negative relationships to BDI scores $(r=-.28)$.

Social support was significantly related to sense of belonging (.63) and negatively related to scores on the hopelessness (STHI Trait) $(r=-.51)$ and BDI scales (-.56). Other significant negative relationships were noted between scores on sense of belonging and scores on the hopelessness (STHI Trait) and BDI subscales (-. 63 to -.70). As expected, participants' scores on hopelessness STHI Trait also showed a significant relationship to scores on the BDI $(r=.55)$.

These findings show that (a) the types of abuse are closely related to each other; (b) there is support for a path model because of the relationship between the independent variables, mediator, and dependent variables; and (c) alternatives to the proposed path model can be explored.

\section{Path Analysis}

Figure 1 presents the path analysis for the results of severity-weighted frequency of physical, psychological, and sexual abuse (self- and police reports). In addition, path analyses were completed examining severity-weighted frequency of physical abuse from self-reports only.

Findings presented in Figure 1 indicate that an insecure attachment style did not directly produce a significant increase in severity-weighted frequency of physical abuse, psychological abuse, or severity-weighted frequency of sexual abuse. However, three subscales of the insecure attachment style were also examined separately for their ability to affect partner abuse in a more 


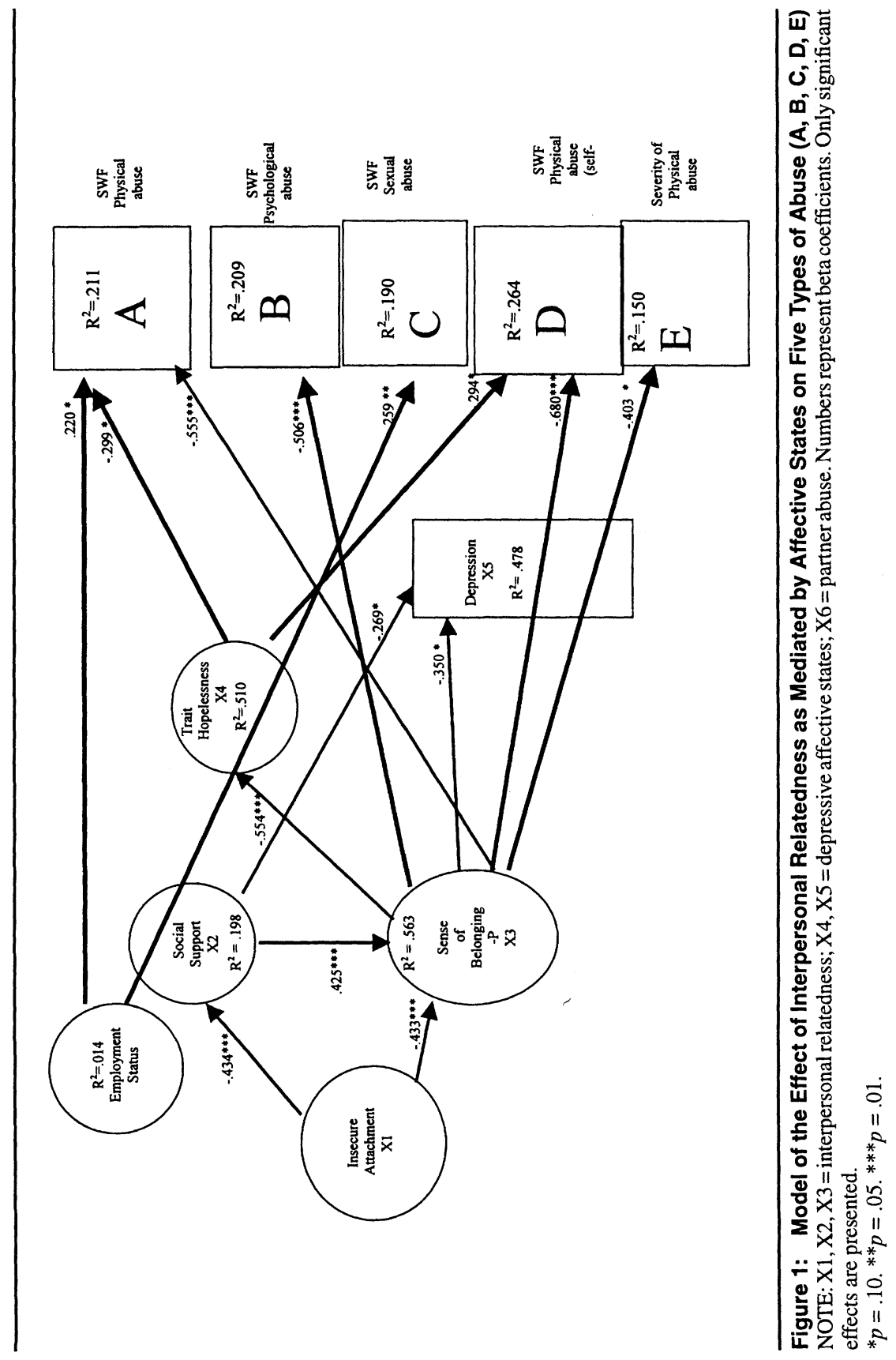


specific model presented in Figure 2. The Need for Approval $(\beta=.303)$, the Discomfort With Closeness, $(\beta=.275)$, and the Preoccupation With Relationships attachment styles $(\beta=-.331)$ had significant direct effects on an increase in the severity-weighted frequency of sexual abuse $\left(R^{2}=.217\right)$. The Relationships as Secondary variable was not included in the analysis because of its low reliabilities in prior studies.

As shown in Figure 1, employment had a direct effect $(\beta=-.220)$ on severityweighted frequency of physical abuse $\left(R^{2}=.211\right)$. Social support did not directly have an impact on increases in any types of partner abuse. Decreased sense of belonging (psychological) affected a significant increase in severity-weighted frequency of physical partner abuse $\left(R^{2}=.211, n=69, \beta=\right.$ $-.555)$. Sense of belonging (psychological) had significant direct negative effects on Severity of psychological abuse $\left(R^{2}=.209, n=69, \beta=-.506\right)$. Decreased sense of belonging (psychological) affected a significant increase in severity-weighted frequency of sexual abuse $\left(R^{2}=.190, n=69, \beta=-.259\right)$. Thus, Hypothesis 1 was supported in four of the five models.

The indirect effects of attachment styles, employment, social support, and sense of belonging on partner abuse as mediated through trait hopelessness and depression were tested. Insecure attachment styles had only indirect effects on trait hopelessness through sense of belonging. Trait hopelessness had a direct path to severity-weighted frequency of physical abuse.

In line with recent research, we rescored the attachment measure into two subscales: Discomfort With Closeness and Anxiety Over Relationships. The path coefficients were about the same as or somewhat lower than they were for the three-scale model. However, only Discomfort With Closeness and not Anxiety Over Relationships was significant. Thus, despite some overlap among the three subscales of attachment, they proved to be better predictors than when two subscales were used.

The impact of perceived social support was indirectly affected by hopelessness through sense of belonging. There were no significant direct relationships of social support and hopelessness in any of these models. When SOBI-P was included in the path, social support had a direct effect on SOBI-P when mediated by hopelessness in predicting weighted frequency of physical partner abuse. The effect of insecure attachment on partner abuse did not have significant indirect effects on depression although attachment styles had significant indirect effects on depression through sense of belonging. The effect of perceived social support on partner abuse through depression was not statistically significant in any of the models tested. Although perceived social support had a direct effect on depression and indirect links with depression through sense of belonging, as noted in all models, depression did not 


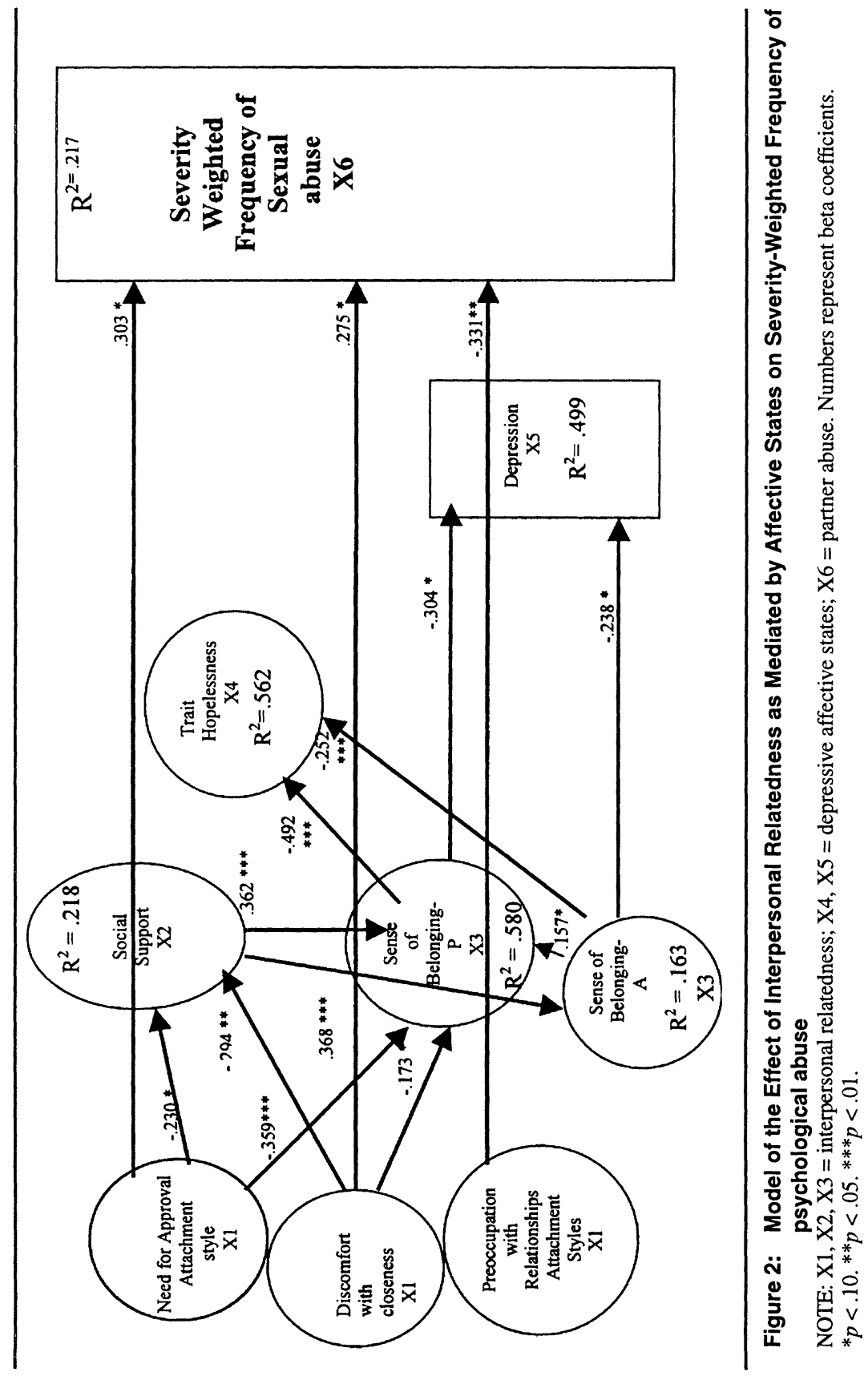


affect any types of partner abuse. Hypothesis 3 was not supported in any of the models tested.

Findings presented in Figure 1 indicate that although both SOBI-P had significant relationships with hopelessness, hopelessness had effects only on severity-weighted frequency of physical abuse. Two models of the severityweighted frequency of physical abuse thus supported Hypothesis 4 .

Although sense of belonging (SOBI-P) had a significant effect on depression, depression had no significant direct effect on partner abuse. Thus, Hypothesis 5 was not supported by the data in any of the models.

\section{DISCUSSION}

The reports of abusive behaviors ranged from minor and moderate verbal abuse to very serious physical abuse producing physical injury to the victim. Similar to what women report in other studies (Straus \& Gelles, 1988), the men reported more psychological abuse than other forms of abuse. The much lower rates of reported physical abuse could have been influenced by the fear that, despite assurances of confidentiality, they would be found in violation of their probation, or psychological abuse is simply more common.

Employment status had a significant positive relationship in two of the models with physical abuse. This was not in the expected direction. The job setting may increase opportunities for male peer support for violence, which in turn may increase partner abuse (DeKeseredy \& Kelly, 1995).

The findings supported an indirect effect on partner abuse through sense of belonging but no direct effect. Social support is a multidimensional variable (House, 1981; Schaefer, Coyne, \& Lazarus, 1981). The single dimension employed in this study may not have been adequate to uncover direct effects. The lack of significance in direct effects of social support may in part be explained with findings by DeKeseredy and Kelly (1995) showing that support from male peers might have different effects than support from family members. Male peer support may actually increase partner abuse, canceling other forms of support that decrease violence. More specific measures of social support may be needed.

Sense of belonging (or the lack of) was the best predictor of most forms of partner abuse and accounted for the majority of the variance within the models. Decreased sense of belonging (psychological) predicted an increase in severity-weighted frequency of physical partner abuse and severity of partner abuse through direct and indirect effects. The analysis also showed that most of the other interpersonal relatedness variables have indirect effects to partner abuse through sense of belonging. 
Hopelessness failed to predict partner abuse in the expected direction. Less hopelessness was related to physical abuse. This may be related to an increased sense of power gained after physically abusing his partner. For a person of color who is likely to feel powerless in our society, this renewed sense of power may reduce the sense of hopelessness (Pinderhughes, 1988). Other studies have also linked perceived powerlessness with misuse of power and marital conflict (Bugental \& Lewis, 1999; Sagrestano, Heavey, \& Christensen, 1999). Alternately, hopelessness may also be difficult to assess in individuals who may be unwilling to reveal their vulnerability.

In the majority of the models tested, there was no evidence that depression was linked to partner abuse. There was evidence that other interpersonal variables were associated with depression, specifically social support and sense of belonging. Sense of belonging in particular may be a mediator between depression and partner abuse, which is the reverse direction in the model we proposed.

The results of the study indicate that the interpersonal relatedness variables were connected to partner abuse mainly through sense of belonging. The strongest direct predictor of the violence was sense of belonging, supporting its applicability in clinical practice with this population and community organizing with this population. Most of the earlier data on partner abuse have come from Caucasian populations. Interpersonal relatedness concepts can have vastly different meanings when doing research on subcultures. Being African American and male in a predominantly Caucasian society that may not value these traits may also have an effect on attachment styles, as African Americans may impart significantly different meanings to their interpersonal relationships than the majority culture (Hunter \& Davis, 1994).

It appears that sense of belonging acts as a mediator between attachment styles and partner abuse. That is, the model suggests that insecure attachment leads to a low sense of belonging, which leads to partner abuse. Also, the effect of SOBI-P increased as hopelessness and depression entered in the equation. SOBI-A's effects, however, decreased slightly as hopelessness entered the equation. This may indicate that the antecedents to sense of belonging are vastly different than the psychological components.

In an alternate model (presented in Figure 2), components of insecure attachment style (Need for Approval, Discomfort With Closeness, and Preoccupation With Relationships) were linked to one form of abuse, severity-weighted frequency of sexual abuse. This finding is consistent with findings from other studies where these types of attachment styles were associated with abusive behaviors in men (e.g., Dutton, van Ginkel, et al., 1996). The Need for Approval attachment style characterizes both fearful and preoccupied (anxious/ambivalent) attachment styles, whereas Discom- 
fort With Closeness is central to the conceptualization of avoidant attachment. In particular, Hudson and Ward (1997) proposed that the preoccupied type of abuser would be more likely to commit rape and sexual violence than persons with other types of attachment styles.

Another notable finding in the present study is that Preoccupation With Relationships was associated with decreased sexual abuse, whereas the other two forms of insecure attachment styles were associated with an increased severity of sexual abuse. Stosny (1993) speculated that the single most important element of attachment abuse is the self-constructed perceptions by abusers. If they believe that they are unlovable or unloving, this belief will create a continual rejection anxiety and a distrust of anyone who they perceive as pretending to love them. Stosny noted that because of the insecure attachment and inability to self-regulate negative affect (such as hopelessness and depression), abusers will continue to attempt to control their own feelings by controlling their attachment figures through dominance, manipulation, coercion, and force. There was evidence of an indirect path between insecure attachment styles and abuse through sense of belonging.

The limitations of this study point to some suggestions for further research. Limitations include the small sample size and self-reports from abusers. The men in the study were all arrested for domestic violence, which suggests that their abusive behaviors may have been more severe for these men than for other abusers. Future studies should use larger more representative samples and reports on violence and some other behaviors from partners. Despite these limitations, the findings provide an initial understanding of some of the key variables related to partner abuse by African American men and can further our understanding of how sense of belonging influences partner abuse These findings can also be used to further develop intervention programs for men who batter.

\section{REFERENCES}

Abraham, L. Y., Metalsky, G. I., \& Alloy, L. B. (1989). Hopelessness depression: A theory-based subtype of depression. Psychological Review, 96(2), 358-372.

Allen-Meares, P., \& Burman, S. (1995). The endangerment of African American men: An appeal for social work action. Social Work, 40(2), 268-274.

Bartholomew, K., \& Horowitz, L. M. (1991). Attachment styles among young adults: A test of a four-category model. Personality \& Social Psychology, 61(2), 226-244.

Batgos, J., \& Leadbeater, B. J. (1993). Parental attachment, peer relations, and dysphoria in adolescence. In M. B. Sperling \& W. H. Berman (Eds.), Attachment in adults: Clinical and developmental perspectives (pp. 155-178). New York: Guilford. 
Beck, A. T., Brown, G., Berchick, R. J., Stewart, B. L., \& Steer, R. A. (1990). Relationship between hopelessness and ultimate suicide: A replication with psychiatric outpatients. American Journal of Psychiatry, 147(2), 190-195.

Beck, A. T., Steer, R. A., \& Garbin, M. G. (1988). Psychometric properties of the Beck Depression Inventory: Twenty-five years of evaluation. Clinical Psychology Review, 8, 77-100.

Brandt, P., \& Weinert, C. (1981). The PRQ: A social support measure. Nursing Research, 30, 277-280.

Bugental, D. B., \& Lewis, J. C. (1999). The paradoxical misuse of power by those who see themselves as powerless: How does it happen? Journal of Social Issues, 55(1), 51-64.

Davidovich, J. R. (1990). Men who abuse their spouses: Social and psychological supports. Journal of Offender Counseling, Services \& Rehabilitation, 15(1) 27-44.

DeKeseredy, W. S. (1988). Woman abuse in dating relationships: The relevance of social support theory. Journal of Family Violence, 3(1), 1-11.

DeKeseredy, W. S., \& Kelly, K. (1995). Sexual abuse in Canadian university and college dating relationships: The contribution of male peer support. Journal of Family Violence, 10(1), 41-53.

Derogatis, L. R. (1975). The Brief Symptom Inventory. Baltimore: Clinical Psychometric Research.

Diamond, D., \& Blatt, S. J. (1994). Internal working models and the representational world in attachment and psychoanalytic theories. In M. B. Sperling \& W. H. Berman (Eds.), Attachment in adults: Clinical and developmental perspectives (pp. 72-97). New York: Guilford.

Dutton, D. G., Saunders, K., Starzomski, A., \& Bartholomew, K. (1994). Intimacy-anger and insecure attachment as precursors of abuse in intimate relationships. Journal of Applied Social Psychology, 24(15), 1367-1386.

Dutton, D. G., Starzomski, A., \& Ryan, L. (1996). Antecedents of abusive personality and abusive behavior in wife assaulters. Journal of Family Violence, 11(2), 113-132.

Dutton, D. G., van Ginkel, C., \& Landolt, M. A. (1996). Jealousy, intimate abusiveness, and intrusiveness. Journal of Family Violence, 11(4), 411-423.

Ellison, G. (1983). Spiritual well-being: Conceptualization and measurement. Journal of Psychology and Theology, 11(4), 330-340.

Feeney, J. A., Noller, P., \& Hanrahan, M. (1994). In M. B. Sperling \& W. H. Berman (Eds.), Attachment in adults: Clinical and developmental perspectives (pp. 128-154). New York: Guilford.

Greenfield, L. A., Rand, M. R., Craven, D., Klaus, P. A., Perkins, C. A., Ringel, C., Warchol, G., Maston, C., \& Fox, J. A. (1998). Violence by intimates: Analysis of data on crimes by current or former spouses, boyfriends, and girlfriends. Washington, DC: U.S. Department of Justice, Bureau of Justice Statistics.

Grimm, P. M. (1990). Hope, affect, psychological status and the cancer experience. Dissertation Abstracts International, 50(9-B), 3918-3919.

Hagerty, B.M.K., Lynch-Sauer, J., Patusky, K. L., \& Bouwsema, M. (1993). An emerging theory of human relatedness. Image, 25(4), 291-296.

Hagerty, B.M.K., Lynch-Sauer, J., Patusky, K. L., Bouwsema, M., \& Collier, P. (1992). Sense of belonging: A vital mental health concept. Archives of Psychiatric Nursing, 6(3), 172-177.

Hagerty, B.M.K., \& Patusky, K. (1995). Developing a measure of sense of belonging. Nursing Research, 44(1), 9-13.

Hagerty, B. M., \& Williams, R. A. (1999). The effects of sense of belonging, social support, conflict and loneliness on depression. Nursing Research, 48(4), 215-219. 
Hagerty, B.M.K., Williams, R. A., Coyne, J. C., \& Early, M. (1996). Sense of belonging and indicators of social and psychological function. Archives of Psychiatric Nursing, 10(4), 235-244.

Hampton, R. L., Carillo, K., \& Kim, J. (1998). Violence in communities of color. In R. Carrillo \& J. Tello (Eds.), Family violence and men of color (pp. 1-30). New York: Springer.

Hazan, C., \& Shaver, P. (1987). Romantic love conceptualized as an attachment process. Journal of Personality \& Social Psychology, 52(3), 511-524.

Hirschi, T. (1969). Causes of delinquency. Berkeley: University of California Press.

Holtzworth-Munroe, A., Smutzler, N., \& Bates, L. (1997). A brief review of the research on husband violence. Aggression and Violent Behavior, 2(3), 285-307.

House, J. (1981). Work stress and social support. Reading, MA: Addison-Wesley.

Hudson, S. M., \& Ward, T. (1997). Intimacy, loneliness, and attachment style in sexual offenders. Journal of Interpersonal Violence, 12(3), 323-339.

Hunter, A. G., \& Davis, J. E. (1994). Hidden voices of black men: The meaning, structure, and complexity of manhood. Journal of Black Studies, 25(1), 20-40.

Jasinski, J. L., \& Williams, L. M. (1998). Partner violence: A comprehensive review of 20 years of research. Thousand Oaks, CA: Sage.

Lackey, C., \& Williams, K. R. (1995). Social bonding and the cessation of partner violence across generations. Journal of Marriage and the Family, 57, 295-305.

Lin, N., Dean, A., \& Ensel, W. (1981). Social support scales: A methodological note. Schizophrenia Bulletin, 7(1), 73-89.

Lockhart, L., \& White, B. W. (1989). Understanding marital violence in the Black community. Journal of Interpersonal Violence, 4(12), 421-436.

Lopez, F. G. (1995). Contemporary attachment theory: An introduction with implications for counseling psychology. The Counseling Psychologist, 23(3), 395-415.

Melges, F. T., \& Bowlby, J. (1969). Types of hopelessness in psychopathological process. Archives of General Psychiatry, 20, 690-699.

Murphy, C. M., Meyer, S. L., \& O'Leary, K. D. (1993). Family of origin violence and MCMI-II psychopathology among partner assaultive men. Violence and Victims, 8(2), 165-176.

Norbeck, J. S., Lindsey, A. M., \& Carrieri, V. L. (1981). The development of an instrument to measure social support. Nursing Research, 30(5), 264-269.

Pinderhughes, E. (1988). Legacy of slavery: The experience of Black families in America. In P. Murkin (Ed.), The social and political contexts of family therapy. Boston: Allyn \& Bacon.

Roberts, N., \& Noller, P. (1998). The associations between adult attachment and couple violence: The role of communication patterns and relationship satisfaction. In J. A. Simpson \& W. S. Rholes (Eds.), Attachment theory and close relationships (pp. 317-350). New York: Guilford.

Rodenburg, F. A., \& Fantuzzo, J. W. (1993). The measure of wife abuse: Steps toward the development of a comprehensive assessment technique. Journal of Family Violence, 8(3), 203-225.

Sagrestano, L. M., Heavey, C. L., \& Christensen, A. (1999). Perceived power and physical violence in marital conflict. Journal of Social Issues, 55(1), 65-79.

Schaefer, C., Coyne, J. C., \& Lazarus, R. S. (1981). The health related functions of social support. Journal of Behavioral Medicine, 4(1), 381-406.

Stosny, S. (1993). Love without violence: A new treatment for spouse abusers (Doctoral dissertation, University of Maryland, 1990). Dissertation Abstracts International, 54(6-A), 2324. 
Straus, M. A., \& Gelles, R. J. (1988). Violence in American families: How much is there and why does it occur? In C. C. Chilman, F. Cox, \& E. Nunnally (Eds.), Troubled relationships (pp. 141-162). Newbury Park, CA: Sage.

Tolman, R. M., \& Bennett, L. W. (1990). A review of quantitative research on men who batter. Journal of Interpersonal Violence, 5(1), 87-118.

Weinert, C., \& Brandt, P. A. (1987). Measuring social support with the Personal Resource Questionnaire. Western Journal of Nursing Research, 9(4), 589-602.

Williams, O. (1998). Healing and confronting the African-American male who batters. In R. Carrillo \& J. Tello (Eds.), Family violence and men of color (pp. 74-94). New York: Springer.

Larry B. Rankin, Ph.D., R.N., is an assistant professor in nursing at Eastern Michigan University where he teaches on the topics of diversity, psychiatric nursing, and nursing management. His research interests focus on violence in African American communities, personality disorders and violence, perpetrators of domestic violence, and leadership behaviors. He is a group therapy facilitator and staff nurse in inpatient and outpatient mental health settings and has worked as a survey researcher and group facilitator for a probation department.

Daniel G. Saunders, Ph.D., is an associate professor at the University of Michigan's School of Social Work where he teaches courses on direct practice and domestic violence. He is codirector of the university's Interdisciplinary Research Program on Violence Across the Lifespan. His research on domestic violence focuses on abuser types and treatment, the traumatic aftermath of violence victimization, and the attitudes and responses of professionals and the public to woman abuse. He has consulted for the Department of Defense, the National Institute of Justice, the National Institute of Mental Health, and many other agencies. His professional publications have appeared in numerous journals and books.

Reg A. Williams is an associate professor at the University of Michigan School of Nursing and is also an adjunct clinical specialist at the University of Michigan Medical Center in the Mood and Anxiety Disorder Program. His research focus is on depression, stress, and coping. He has a current study funded by the Department of Defense, "Tri-Service Nursing Research Program," testing a cognitive-behavioral intervention to prevent the development of depression. He has numerous research publications in professional journals and two books. 